\title{
Joint detection of multiple immunohistochemical indices and clinical significance in breast cancer
}

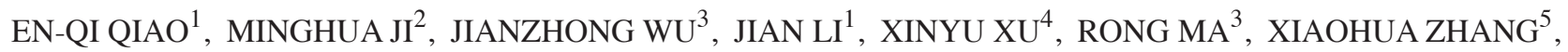 \\ YUEJUN HE ${ }^{6}$, QUANBIN ZHA ${ }^{6}$, XUE SONG ${ }^{1}$, LIWEI ZHU ${ }^{1}$ and JI-HAI TANG ${ }^{1}$ \\ Departments of ${ }^{1}$ General Surgery and ${ }^{2}$ Radiotherapy; ${ }^{3}$ Research Center for Clinical Oncology; ${ }^{4}$ Department of Pathology, \\ Jiangsu Cancer Hospital, Affiliated to Nanjing Medical University, Nanjing, Jiangsu 210009; ${ }^{5}$ Nanjing Medical \\ University, Nanjing, Jiangsu 210029; ${ }^{6}$ Xuzhou Medical College, Xuzhou, Jiangsu 221000, P.R. China
}

Received November 15, 2012; Accepted April 17, 2013

DOI: $10.3892 / \mathrm{mco} .2013 .111$

\begin{abstract}
Breast cancer is one of the most common malignancies in women. This study was conducted to analyze the association between the expressions of eight immunohistochemical (IHC) indices and clinicopathological characteristics in breast cancers (BCs) and investigate the clinical significance. IHC Envision ldpe-g-nvp was used to detect the expression of estrogen receptor (ER), progesterone receptor (PR), human epidermal growth factor receptor-2 (HER2), vascular endothelial growth factor (VEGF), epidermal growth factor receptor (EGFR), p53, type II topoisomerase (TOPO II) and Ki-67 in postoperative paraffin blocks of 286 cases of invasive $\mathrm{BC}$ and statistically analyzed their correlations with clinicopathological characteristics. The positive rates of ER, PR, HER2, VEGF, p53, EGFR, TOPO II and Ki-67 expression were 62.24, 41.96, $57.34,53.85,81.82,46.85,54.55$ and $69.93 \%$, respectively. ER expression was negatively correlated with age, tumor size and histological grade $(\mathrm{P}<0.05)$ and $\mathrm{PR}$ expression was negatively correlated with age and histological grade $(\mathrm{P}<0.05)$. Among the ER, PR and c-erbB-2 statuses, a significant correlation was observed between ER expression and PR status $(\mathrm{P}=0.0000)$, whereas the expression of ER and PR exhibited a negative correlation with HER2 status $(\mathrm{P}<0.05)$. We also demonstrated a significant correlation between EGFR expression and lymph node metastasis $(\mathrm{P}=0.0240)$, $\mathrm{p} 53$ expression and tumor size $(\mathrm{P}=0.0300), \mathrm{p} 53$ and Ki-67 expression and histological grade $(\mathrm{P}<0.05)$ and the expressions of VEGF, EGFR, p53, TOPO II,
\end{abstract}

Correspondence to: Professor Ji-Hai Tang, Department of General Surgery, Jiangsu Cancer Hospital, Affiliated to Nanjing Medical University, Nanjing, Jiangsu 210009, P.R. China

E-mail: tangjinhaidoctor@sina.cn

Dr Jianzhong Wu, Research Center for Clinical Oncology, Jiangsu Cancer Hospital, Affiliated to Nanjing Medical University, Nanjing, Jiangsu 210009, P.R. China

E-mail:wujzh1528@126.com

Key words: breast carcinoma, clinicopathological characteristics, immunohistochemical index, breast cancer subtype
Ki-67 and HER 2 status $(\mathrm{P}<0.05)$. In addition, the Luminal B and HER2/neu subtypes exhibited a close correlation with age $(\mathrm{P}<0.01)$, while the HER2/neu and triple-negative subtypes were positively correlated with poor histological grade $(\mathrm{P}<0.05)$. In conclusion, there is a definite correlation between IHC indices and clinicopathological characteristics in BCs. Combined detection of these indices may be significant in the evaluation of biological behavior and prognosis of $\mathrm{BC}$ and thus in the diagnosis and comprehensive treatment of this disease.

\section{Introduction}

Breast cancer $(\mathrm{BC})$ is one of the most common malignancies in women. There are $>1,000,000$ new cases diagnosed annually worldwide. A marked increase in incidence occurs annually and in particular among women of younger age, which poses a serious threat to women's physical and mental health (1). The occurrence, progression and prognosis of various types of cancer are complex processes, involving numerous factors, genes and proteins. Therefore, it is difficult to determine the biological behavior and prognosis of $\mathrm{BC}$ based on the assessment of a single factor.

Immunohistochemical (IHC) detection has become essential to many malignancies and plays a key role in tumor diagnosis, treatment and prognostic assessment. In this study, we collected 286 cases of invasive BC, confirmed at our pathology laboratory, detected the expression of estrogen receptor (ER), progesterone receptor (PR), human epidermal growth factor receptor-2 (HER2), vascular endothelial growth factor (VEGF), epidermal growth factor receptor (EGFR), p53, type II toposomerase (TOPO II) and Ki-67 proteins by IHC and analyzed the associations between these indicators and the clinicopathological characteristics, designed to further investigate the associations of the expressions of hormone receptors, oncogenes and proteins with $\mathrm{BC}$ biological behavior and prognosis, in order to guide clinical diagnosis and comprehensive treatment.

\section{Materials and methods}

Materials. Tissue samples from 286 patients with invasive BC were collected in Jiangsu Cancer Hospital, Affiliated to 
Table I. Association between the expressions of ER, PR and HER2 in BCs and clinicopathological characteristics [cases, (\%)].

\begin{tabular}{|c|c|c|c|c|c|c|c|c|c|}
\hline \multirow{2}{*}{$\begin{array}{l}\text { Clinicopathological } \\
\text { characteristics }\end{array}$} & \multirow[b]{2}{*}{ No. } & \multicolumn{2}{|c|}{ ER } & \multicolumn{2}{|c|}{ PR } & \multicolumn{2}{|c|}{ HER2 } & \multicolumn{2}{|c|}{$\mathrm{ER}$ and $\mathrm{PR}$} \\
\hline & & $(+)$ & P-value & $(+)$ & P-value & $(+)$ & P-value & $(+)$ & P-value \\
\hline \multicolumn{10}{|l|}{ Age (years) } \\
\hline$\leq 50$ & 140 & $100(71.42)$ & $0.0260^{\mathrm{a}}$ & $78(55.71)$ & $0.0011^{\mathrm{b}}$ & $74(52.86)$ & 0.2280 & $72(51.43)$ & $0.0033^{\mathrm{b}}$ \\
\hline$>50$ & 146 & $78(54.80)$ & 4.9284 & $42(28.76)$ & 10.6550 & $90(61.64)$ & - & $40(20.40)$ & 8.6617 \\
\hline \multicolumn{10}{|l|}{ Tumor size $(\mathrm{cm})$} \\
\hline$\leq 2$ & 164 & $114(69.51)$ & $0.0370^{\mathrm{a}}$ & $74(45.12)$ & 0.3740 & $92(56.10)$ & 0.7270 & $70(42.68)$ & 0.3170 \\
\hline$>2$ & 122 & $64(52.45)$ & 4.3281 & $46(37.70)$ & - & $72(59.02)$ & - & $42(34.42)$ & - \\
\hline \multicolumn{10}{|l|}{$\begin{array}{l}\text { Lymph node } \\
\text { metastasis }\end{array}$} \\
\hline Positive & 134 & $82(61.19)$ & 0.8090 & $50(37.31)$ & 0.2900 & $84(62.69)$ & 0.2250 & $44(32.84)$ & 0.1460 \\
\hline Negative & 152 & $96(63.16)$ & - & $70(46.05)$ & - & $80(52.63)$ & - & 68 (44.74) & - \\
\hline \multicolumn{10}{|l|}{$\begin{array}{l}\text { Histological } \\
\text { grade }\end{array}$} \\
\hline I-II & 208 & $140(67.31)$ & $0.0410^{\mathrm{a}}$ & $98(47.12)$ & $0.0410^{\mathrm{a}}$ & $118(56.73)$ & 0.8090 & $92(44.23)$ & $0.0430^{\mathrm{a}}$ \\
\hline III & 78 & $38(48.71)$ & 4.1706 & $22(28.21)$ & 4.1649 & $46(58.97)$ & - & $20(25.64)$ & 4.1141 \\
\hline
\end{tabular}

${ }^{\mathrm{a}} \mathrm{P} \leq 0.05,{ }^{\mathrm{b}} \mathrm{P} \leq 0.01$, the $\chi^{2}$ values appeared when $\mathrm{P} \leq 0.05$. BCs, breast cancers; ER, estrogen receptor; PR, progesterone receptor; HER2, human epidermal growth factor receptor-2.

Nanjing Medical University, between February, 2011 and July, 2012. All the samples were primary cancers, with complete medical records and a confirmed diagnosis. The patients had not received any treatment prior to surgery. All patients were female, aged 28-79 years (median, 51 years). A total of 146 cases were $>50$ years of age and the remaining 140 cases were $\leq 50$ years of age. The tumor size was $>2 \mathrm{~cm}$ in 122 cases and $\leq 2 \mathrm{~cm}$ in 164 cases. Lymph node metastasis was identified in 134 cases and 152 cases presented with non-metastatic lymph nodes, as determined by IHC. Histological grades were classified according to the WHO histological classification standards for evaluation of BC (2003). Among the cases there were 24 grade I, 184 grade II and 78 grade III cases. Monoclonal antibodies against ER, PR, HER2, VEGF, EGFR, p53, TOPO II and Ki-67, as well as IHC kits, were purchased from Zhongshan Jinqiao Biotechnology Co., Ltd. (Beijing, China).

Methods. The samples were fixed in $10 \%$ neutral formalin, desiccated and embedded in paraffin, then sliced into $4-\mu \mathrm{m}$ sections. Envision ldpe-g-nvp was used as the staining method. The primary antibody dilution and process of staining were performed according to the manufacturer's instructions. Equivalent phosphate-buffered saline (PBS) was used as a negative control for primary antibodies. The results were observed under a microscope. The staining of HER2 was mainly localized in the membrane, EGFR was localized mainly in the cytoplasm and to a limited extent in the membrane, VEGF was localized in the cytoplasm and the membrane, whereas ER, PR, p53, TOPO II and Ki-67 were localized in the nucleus (Fig. 1). Cells were classified according to the positive rate and colour intensity as follows: negative (-), number of positive cells $<5 \%$; weak positive $(+)$,
Table II. Association among the expressions of ER, PR and HER2 in BCs [cases, (\%)].

\begin{tabular}{|c|c|c|c|c|c|}
\hline \multirow[b]{2}{*}{ Indices } & \multirow[b]{2}{*}{ No. } & \multicolumn{2}{|c|}{ PR } & \multicolumn{2}{|c|}{ HER2 } \\
\hline & & $(+)$ & P-value & $(+)$ & $\mathrm{P}$-value \\
\hline \multicolumn{6}{|l|}{ ER } \\
\hline$(+)$ & 178 & $112(66.29)$ & $0.0000^{\mathrm{b}}$ & $80(44.94)$ & $0.0001^{\mathrm{b}}$ \\
\hline$(-)$ & 108 & $8(7.41)$ & 42.5299 & $84(77.78)$ & 14.8123 \\
\hline \multicolumn{6}{|l|}{ PR } \\
\hline$(+)$ & 120 & - & - & $54(45.00)$ & $0.0110^{\mathrm{a}}$ \\
\hline$(-)$ & 166 & - & - & $110(66.27)$ & 6.4381 \\
\hline \multicolumn{6}{|l|}{ HER2 } \\
\hline$(+)$ & 164 & $54(32.93)$ & $0.0110^{\mathrm{a}}$ & - & - \\
\hline$(-)$ & 122 & $66(54.10)$ & 6.4381 & - & - \\
\hline
\end{tabular}

${ }^{\mathrm{a}} \mathrm{P} \leq 0.05,{ }^{\mathrm{b}} \mathrm{P} \leq 0.01$, the $\chi^{2}$ values appeared when $\mathrm{P} \leq 0.05$. BCs, breast cancers; ER, estrogen receptor; PR, progesterone receptor; HER2, human epidermal growth factor- 2 .

pale brown particles, number of positive cells $6-25 \%$; positive $(++)$, brown particles, number of positive cells $26-50 \%$; strong positive $(+++)$, dark brown particles, number of positive cells $>50 \%$. The results of the assessment of HER2-positive cells were in accordance with those of a previous study (2).

Statistical analysis. Statistical analysis was performed with SPSS software v. 16.0 and the enumeration data were compared with the Chi-square $\left(\chi^{2}\right)$ test. $\mathrm{P} \leq 0.05$ was considered to indicate a statistically significant difference. 
Table III. Association between the expressions of VEGF, EGFR, p53, TOPO II and Ki67 in BCs and clinicopathological characteristics [cases, $(\%)]$.

\begin{tabular}{|c|c|c|c|c|c|c|c|c|c|c|c|}
\hline \multirow{2}{*}{$\begin{array}{l}\text { Clinicopathological } \\
\text { characteristics }\end{array}$} & \multirow{2}{*}{ No. } & \multicolumn{2}{|c|}{ VEGF } & \multicolumn{2}{|c|}{ EGFR } & \multicolumn{2}{|c|}{ p53 } & \multicolumn{2}{|c|}{ TOPO II } & \multicolumn{2}{|c|}{$\mathrm{Ki}-67$} \\
\hline & & $(+)$ & P-value & $(+)$ & P-value & $(+)$ & P-value & $(+)$ & $\mathrm{P}$-value & $(+)$ & $\mathrm{P}$-value \\
\hline
\end{tabular}

Age (years)
$\leq 50$
$>50$

Tumor size $(\mathrm{cm})$

$\leq 2$

$>2$

$140 \quad 68(48.57)$

$146 \quad 86(58.90)$

$0.2150112(80.00)$

$122(83.56)$

0.3047

$64(45.71) \quad 0.7893$

$70(50.00)$

$\begin{array}{lll}0.2850 & 104(74.29) \quad 0.2660\end{array}$

$164 \quad 86(52.44)$

$0.6960132(80.49)$

$0.6320 \quad 64(39.02)$

\begin{tabular}{ll}
$0.0300^{\mathrm{a}} \quad 86(52.44)$ \\
\hline
\end{tabular}

$\begin{array}{lll}0.5580 & 110(67.07) \quad 0.3880\end{array}$

$12268(55.74)$

$102(83.61)$

- $\quad 70(57.38) \quad 4.7314 \quad 70(57.38)$

- $\quad 90(73.77)$

Lymph node

metastasis

Positive

Negative

$134 \quad 80(59.70)$

$0.1870120(89.55)$

$0.0240^{\mathrm{a}} 56(41.79)$

0.2550

$70(52.24)$

$0.6030 \quad 96(71.64)$

0.6750

Histological

grade

\begin{tabular}{|c|c|c|c|c|c|c|c|c|c|c|}
\hline I-II & $208110(52.88)$ & 0.7060 & $168(80.77)$ & 0.5950 & $86(41.35)$ & $0.0310^{\mathrm{a}}$ & $108(51.92)$ & 0.3040 & $134(64.42)$ & $0.0190^{\mathrm{a}}$ \\
\hline III & $78 \quad 44(56.41)$ & - & $66(84.62)$ & - & $48(61.54)$ & 4.6443 & $48(61.54)$ & - & $66(84.62)$ & 5.5000 \\
\hline
\end{tabular}

${ }^{\mathrm{a} P} \leq 0.05,{ }^{\mathrm{b}} \mathrm{P} \leq 0.01$, the $\chi^{2}$ values appeared when $\mathrm{P} \leq 0.05$. BCs, breast cancers; VEGF, vascular endothelial growth factor; EGFR, epidermal growth factor receptor; TOPO II, type II topoisomerase.

Table IV. Association between the expressions of ER, PR and HER2 and the expressions of VEGF, EGFR, p53, TOPO II and Ki67 in BCs [cases, (\%)].

\begin{tabular}{|c|c|c|c|c|c|c|c|c|c|c|c|}
\hline \multirow[b]{2}{*}{ Indices } & \multirow[b]{2}{*}{ No. } & \multicolumn{2}{|c|}{ VEGF } & \multicolumn{2}{|c|}{ EGFR } & \multicolumn{2}{|c|}{ p53 } & \multicolumn{2}{|c|}{ TOPO II } & \multicolumn{2}{|c|}{ Ki-67 } \\
\hline & & $(+)$ & P-value & $(+)$ & P-value & $(+)$ & P-value & $(+)$ & P-value & $(+)$ & P-value \\
\hline \multicolumn{12}{|l|}{ ER } \\
\hline$(+)$ & 178 & $82(46.07)$ & $0.0166^{\mathrm{a}}$ & $144(80.90)$ & 0.7140 & $82(46.07)$ & 0.8090 & $98(55.06)$ & 0.8750 & $120(67.42)$ & 0.4000 \\
\hline$(-)$ & 108 & $72(66.67)$ & 5.7384 & $90(83.33)$ & - & $52(48.15)$ & - & $58(53.70)$ & - & $80(74.07)$ & - \\
\hline \multicolumn{12}{|l|}{ PR } \\
\hline$(+)$ & 120 & $46(38.33)$ & $0.0016^{\mathrm{b}}$ & $92(76.67)$ & 0.1740 & $52(43.33)$ & 0.4730 & $62(51.67)$ & 0.5040 & $78(65.00)$ & 0.2740 \\
\hline$(-)$ & 166 & $108(65.06)$ & 10.0099 & $142(85.54)$ & - & $82(49.40)$ & - & $94(56.63)$ & - & $122(73.49)$ & - \\
\hline \multicolumn{12}{|l|}{ HER2 } \\
\hline$(+)$ & 164 & $102(62.20)$ & $0.0202^{\mathrm{a}}$ & $148(90.24)$ & $0.0020^{\mathrm{b}}$ & $102(62.20)$ & $0.0000^{\mathrm{b}}$ & $112(68.29)$ & $0.0000^{\mathrm{b}}$ & $130(79.27)$ & $0.0050^{\mathrm{b}}$ \\
\hline$(-)$ & 122 & $52(42.62)$ & 5.3917 & $86(70.49)$ & 9.1730 & $32(26.23)$ & 18.1705 & 44 (36.07) & 14.6526 & 70 (57.38) & 7.9717 \\
\hline
\end{tabular}

${ }^{\mathrm{a}} \mathrm{P} \leq 0.05,{ }^{\mathrm{b}} \mathrm{P} \leq 0.01$, the $\chi^{2}$ values appeared when $\mathrm{P} \leq 0.05$. BCs, breast cancers, ER, estrogen receptor; PR, progesterone receptor VEGF, vascular endothelial growth factor; EGFR, epidermal growth factor receptor; TOPO II, type II topoisomerase, HER2; human epidermal growth factor receptor-2.

\section{Results}

Association between the expressions of ER, PR and HER 2 in breast cancers (BCs) and clinicopathological characteristics. As shown in Table I, the positive rates of ER or PR, as well as the double-positive rate of ER and PR, were highest in the lower age group (69.51, 55.71 and $51.43 \%$, respectively). ER expression exhibited a negative correlation with age, tumor size and histological grade $\left(\chi^{2}=4.9284, \mathrm{P}=0.0260 ; \chi^{2}=4.3281\right.$, $\mathrm{P}=0.0370$; and $\chi^{2}=4.1706, \mathrm{P}=0.0410$, respectively), PR expres- sion exhibited a negative correlation with age and histological grade $\left(\chi^{2}=10.6550, \mathrm{P}=0.0011\right.$ and $\chi^{2}=4.1649, \mathrm{P}=0.0410$, respectively) and the double-positive expression of ER and PR also exhibited a negative correlation with age and histological grade $\left(\chi^{2}=8.6617, \mathrm{P}=0.0033\right.$ and $\chi^{2}=4.1141, \mathrm{P}=0.0430$, respectively). However, there was no statistically significant difference among the indices in lymph node metastasis. The positive rate of HER 2 was highest in the lymph node metastasis group (62.69\%); although no correlation with age, tumor size, lymph node metastasis and histological grade was evident. 
Table V. Association among the expressions of VEGF, EGFR, p53, TOPO II and Ki67 in BCs [cases, (\%)].

\begin{tabular}{|c|c|c|c|c|c|c|c|c|c|}
\hline \multirow[b]{2}{*}{ Indices } & \multirow[b]{2}{*}{ No. } & \multicolumn{2}{|c|}{ EGFR } & \multicolumn{2}{|c|}{ p53 } & \multicolumn{2}{|c|}{ TOPO II } & \multicolumn{2}{|c|}{ Ki-67 } \\
\hline & & $(+)$ & P-value & $(+)$ & P-value & $(+)$ & P-value & $(+)$ & P-value \\
\hline \multicolumn{10}{|l|}{ VEGF } \\
\hline$(+)$ & 154 & $132(85.71)$ & 0.19200 & $70(45.45)$ & 0.97900 & $82(53.25)$ & 0.73600 & $108(70.13)$ & 0.95500 \\
\hline$(-)$ & 132 & $102(77.27)$ & - & $64(48.48)$ & - & $74(56.06)$ & - & 92 (69.69) & - \\
\hline \multicolumn{10}{|l|}{ EGFR } \\
\hline$(+)$ & 234 & - & - & $110(40.01)$ & 0.93700 & $118(50.43)$ & $0.03600^{\mathrm{a}}$ & 166 (70.94) & 0.57600 \\
\hline$(-)$ & 52 & - & - & $24(46.15)$ & - & $38(70.08)$ & 4.40160 & 34 (65.38) & - \\
\hline \multicolumn{10}{|l|}{ p53 } \\
\hline$(+)$ & 134 & $110(82.09)$ & 0.93700 & - & - & $92(68.66)$ & $0.00150^{\mathrm{b}}$ & $112(83.58)$ & $0.00083^{b}$ \\
\hline$(-)$ & 152 & $124(81.58)$ & - & - & - & $64(42.11)$ & 10.12500 & $88(57.89)$ & 11.17360 \\
\hline \multicolumn{10}{|l|}{ TOPO II } \\
\hline$(+)$ & 156 & $118(75.64)$ & $0.03600^{\mathrm{a}}$ & $92(58.97)$ & $0.00150^{\mathrm{b}}$ & - & - & $130(83.33)$ & $0.00013^{b}$ \\
\hline$(-)$ & 130 & $116(89.23)$ & 4.40160 & $42(32.31)$ & 10.12500 & - & - & $70(53.85)$ & 14.66030 \\
\hline
\end{tabular}

${ }^{\mathrm{a}} \mathrm{P} \leq 0.05,{ }^{\mathrm{b}} \mathrm{P} \leq 0.01$, the $\chi^{2}$ values appeared when $\mathrm{P} \leq 0.05$. BCs, breast cancers; VEGF, vascular endothelial growth factor; EGFR, epidermal growth factor receptor; TOPO II, type II topoisomerase.

A

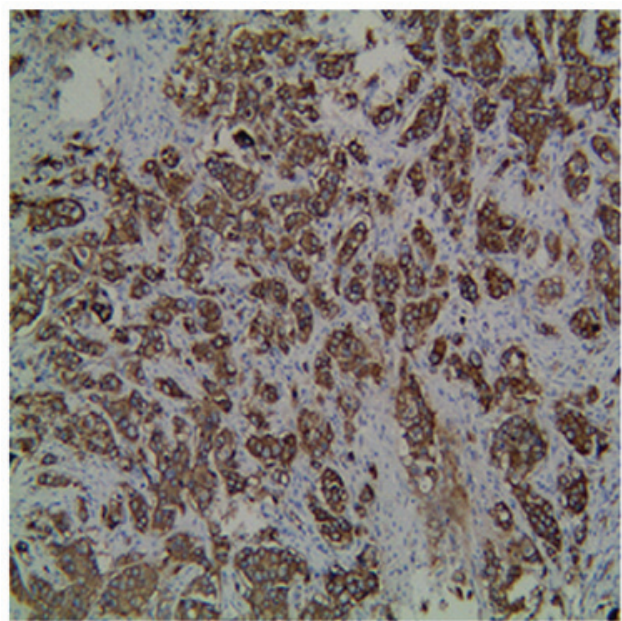

C

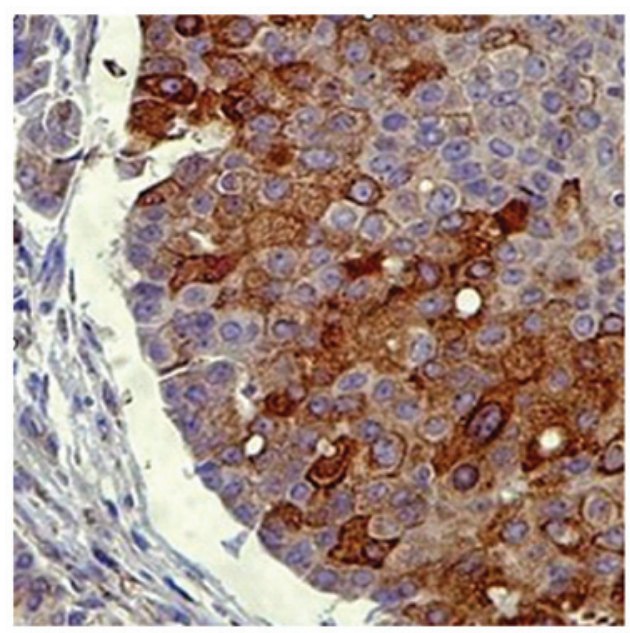

B

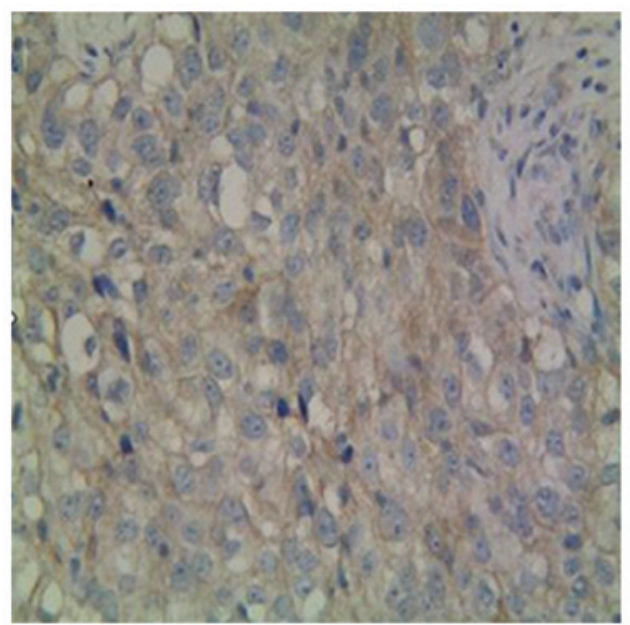

D

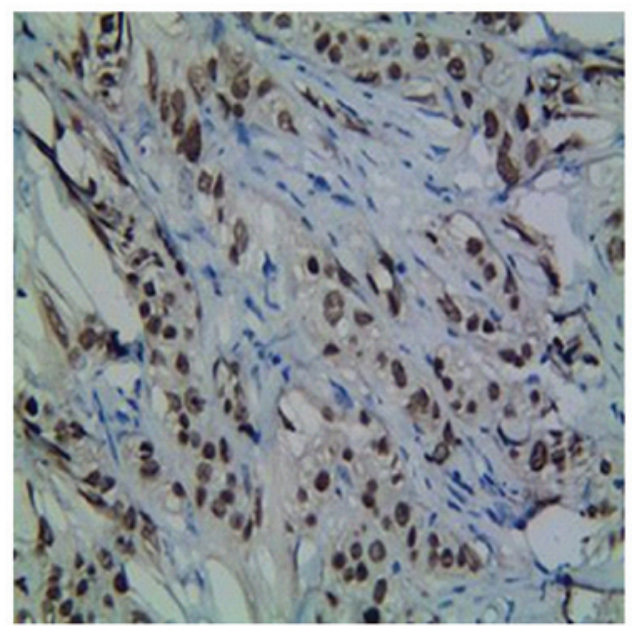

Figure 1. Positive expressions of immunohistochemical (IHC) indices in invasive breast cancer tissues. Indices that (A) exist only in the membrane (human epidermal growth factor receptor-2, HER2), (B) are present mainly in the cytoplasm (epidermal growth factor receptor, EGFR), (C) are present in both the cytoplasm and the membrane (vascular endothelial growth factor, VEGF), (D) are detected only in the nucleus [estrogen receptor (ER), progesterone receptor (PR), p53, type II topoisomerase (TOPO II) and Ki-67] are shown. Images were IHC 3+ or fluorescence in situ hybridisation (FISH)-positive. EnVision (magnification, x100/x400). 
Table VI. Association between the IHC approximate molecular subtypes of BC and clinicopathological characteristics [cases, (\%)].

\begin{tabular}{|c|c|c|c|c|c|c|c|c|c|}
\hline \multirow{2}{*}{$\begin{array}{l}\text { Clinicopathological } \\
\text { characteristics }\end{array}$} & \multirow[b]{2}{*}{ No. } & \multicolumn{2}{|c|}{ Luminal A } & \multicolumn{2}{|c|}{ Luminal B } & \multicolumn{2}{|c|}{$\begin{array}{l}\text { HER2/neu subtype } \\
\text { (non-Luminal) }\end{array}$} & \multicolumn{2}{|c|}{ Triple-negative } \\
\hline & & Yes & P-value & Yes & P-value & Yes & P-value & Yes & P-value \\
\hline \multicolumn{10}{|l|}{ Age (years) } \\
\hline$\leq 50$ & 140 & $28(20.00)$ & 0.7780 & $82(58.57)$ & $0.0020^{\mathrm{b}}$ & $22(15.71)$ & $0.0040^{\mathrm{b}}$ & $12(8.57)$ & 0.8320 \\
\hline$>50$ & 146 & $32(21.92)$ & - & $48(32.87)$ & 9.5156 & $54(36.98)$ & 8.2871 & $14(9.59)$ & - \\
\hline \multicolumn{10}{|l|}{ Tumor size $(\mathrm{cm})$} \\
\hline$\leq 2$ & 164 & $38(23.17)$ & 0.4550 & $78(47.56)$ & 0.5580 & $34(20.73)$ & 0.0670 & $14(8.54)$ & 0.7890 \\
\hline$>2$ & 122 & $22(18.03)$ & - & $52(42.62)$ & - & $42(34.43)$ & - & $12(9.84)$ & - \\
\hline \multicolumn{10}{|l|}{$\begin{array}{l}\text { Lymph node } \\
\text { metastasis }\end{array}$} \\
\hline Positive & 134 & $22(16.42)$ & 0.2080 & $66(49.25)$ & 0.3920 & $40(29.85)$ & 0.4050 & $10(7.46)$ & 0.5250 \\
\hline Negative & 152 & $38(25.00)$ & - & $64(42.11)$ & - & $36(23.68)$ & - & $16(10.52)$ & - \\
\hline \multicolumn{10}{|l|}{$\begin{array}{l}\text { Histological } \\
\text { grade }\end{array}$} \\
\hline I-II & 208 & $50(24.04)$ & 0.1423 & $100(48.08)$ & 0.3040 & $46(22.12)$ & $0.0490^{\mathrm{a}}$ & $12(5.77)$ & $0.0240^{\mathrm{a}}$ \\
\hline III & 78 & $10(12.82)$ & - & $30(38.46)$ & - & $30(38.46)$ & 3.8841 & $14(17.95)$ & 5.0910 \\
\hline
\end{tabular}

${ }^{\mathrm{a} P} \leq 0.05,{ }^{\mathrm{b}} \mathrm{P} \leq 0.01$, the $\chi^{2}$ values appeared when $\mathrm{P} \leq 0.05$. IHC, immunohistochemical; BC, breast cancer; HER 2 , human epidermal growth factor receptor-2.

Association of the expressions of ER, PR and HER2 in BCs. As shown in Table II, the positive rates of ER and PR in the HER2-negative cases (80.33 and $54.10 \%$, respectively) were significantly higher compared to the HER2-positive cases (48.78 and $32.93 \%$, respectively). The expression of PR was closely associated with the ER status $\left(\chi^{2}=42.5299, \mathrm{P}=0.0000\right)$ and the expressions of ER and PR were negatively correlated with HER2 $\left(\chi^{2}=14.8123, \mathrm{P}=0.0001\right.$ and $\chi^{2}=6.4381, \mathrm{P}=0.0110$, respectively).

Association between the expression of VEGF, EGFR, p53, TOPO II and Ki-67 in BCs and clinicopathological characteristics. As shown in Table III, the expression of EGFR was highest in the lymph node metastasis group (89.55\%) and exhibited a positive correlation with lymph node metastasis $\left(\chi^{2}=5.0690, \mathrm{P}=0.0240\right)$. The positive rates of $\mathrm{p} 53$ and $\mathrm{Ki}-67$ were highest in the poor histological grade group (61.54 and $84.62 \%$, respectively), p53 expression was correlated with tumor size and histological grade $\left(\chi^{2}=4.7314, \mathrm{P}=0.0300\right.$ and $\chi^{2}=4.6443, \mathrm{P}=0.0310$, respectively) and $\mathrm{Ki}-67$ expression was correlated with histological grade $\left(\chi^{2}=5.5000, \mathrm{P}=0.0190\right)$. The expressions of VEGF and TOPO II did not statistically differ with age, tumor, lymph node metastasis and histological grade.

Association between the expressions of ER, PR and HER 2 and the expressions of VEGF, EGFR, p53, TOPO II and Ki-67 in $B C$ s. As shown in Table IV, the expression of VEGF exhibited a negative correlation with ER and PR status $\left(\chi^{2}=5.7384\right.$, $\mathrm{P}=0.0166$ and $\chi^{2}=10.0099, \mathrm{P}=0.0016$, respectively) and a positive correlation with HER 2 expression $\left(\chi^{2}=5.3917, \mathrm{P}=0.0202\right)$. The expressions of EGFR, p53, TOPO II and Ki-67 were closely associated with HER 2 status $\left(\chi^{2}=9.1730, \mathrm{P}=0.0020 ; \chi^{2}=18.1705\right.$,
$\mathrm{P}=0.0000 ; \chi^{2}=14.6526, \mathrm{P}=0.0000$ and $\chi^{2}=7.9717, \mathrm{P}=0.0050$, respectively).

Association among the expressions of VEGF, EGFR, p53, TOPO II and Ki-67 in BCs. As shown in Table V, the expression of TOPO II exhibited a negative correlation with EGFR and a positive correlation with p53 and Ki-67 $\left(\chi^{2}=4.40160\right.$, $\mathrm{P}=0.03600 ; \chi^{2}=10.12500, \mathrm{P}=0.00150$ and $\chi^{2}=14.66030$, $\mathrm{P}=0.00013$, respectively). The expression of Ki-67 was significantly correlated with p53 $\left(\chi^{2}=11.17360, \mathrm{P}=0.00083\right)$. The association between the expression of VEGF and the levels of EGFR, p53, TOPO II and Ki-67 was not statistically significant.

Association between the IHC approximate molecular subtypes of $B C$ and clinicopathological characteristics. As shown in Table VI, in all the cases, the percentages of Luminal A, Luminal B, HER2/neu and triple-negative subtype were $20.98,45.45,26.57$ and $9.09 \%$, respectively. The proportion of Luminal A subtype was highest in the non-metastatic lymph node group (25\%) and decreased with increasing histological grade; however, there was no statistically significant difference in these data. The proportion of Luminal B subtype was highest in the lower age group (58.57\%), with a statistically significant difference $\left(\chi^{2}=9.5156, \mathrm{P}=0.0020\right)$. However, it was higher in the poor histological grade group, although the difference was not statistically significant. The proportion of the HER2/neu subtype was highest in the poor histological grade group (38.46\%) and exhibited a statistically significant difference in age and histological grade $\left(\chi^{2}=8.2871, \mathrm{P}=0.0040\right.$ and $\chi^{2}=3.8841, \mathrm{P}=0.0490$, respectively). The proportion of the triple-negative subtype was highest in the poor histological grade group $(17.95 \%)$, the difference was statistically significant $\left(\chi^{2}=5.0910, \mathrm{P}=0.0240\right)$ 
Table VII. Definition and treatment strategies of BC subtypes according to the St. Gallen consensus in 2011.

\begin{tabular}{lll}
\hline Subtypes & \multicolumn{1}{c}{ Definition } & \multicolumn{1}{c}{ Treatment strategies } \\
\hline Luminal A & ER+ and/or PR+, HER2 and Ki-67 & Endocrine therapy \\
low expression $(<14 \%)$ & Endocrine therapy \pm cytotoxic therapy \\
& Luminal B (HER2-negative) & \\
& ER+ and/or PR+, HER2 and Ki-67 & \\
& high expression $(\geq 14 \%)$ & \\
& Euminal B $($ HER2/neu+ $)$ & Endocrine therapy \pm cytotoxic therapy \\
& and Ki-67 uncertain & anti-HER2 therapy \\
Her2/neu & HER2/neu subtype (non-Luminal) & Cytotoxic therapy + anti-HER2 therapy \\
& ER and PR deficiency & \\
HER2 overexpression or proliferation & ER and PR deficiency, HER2 & Cytotoxic therapy \\
\hline
\end{tabular}

$\mathrm{BC}$, breast cancer, ER, estrogen receptor; PR, progesterone receptor; HER2, human epidermal growth factor receptor-2.

and exhibited no correlation with age, tumor size or lymph node metastasis.

\section{Discussion}

Several tumors are hormone-dependent and BC is a typical example. ER and PR play important roles in the growth and differentiation of BCs while their expression levels are decisive factors guiding the endocrine treatment of BCs, and important prognostic markers. Our data demonstrated that the positive rates of ER and PR were 62.24 and $41.96 \%$, which was in agreement with the findings of a previous study (3). Furthermore, this study demonstrated that ER expression decreased with increasing histological grade, indicating that the lower the tumor cell differentiation, the lower the estrogen dependence, thus affecting the sensitivity to hormone therapy. The association between ER expression and lymph node metastasis was diverse in previous studies $(4,5)$. Our results demonstrated that the expression of ER was negatively correlated with age and tumor size and had no correlation with lymph node metastasis. ER expression may not be an independent prognostic factor, as PR and ER are steroid hormone receptors that belong to the nuclear receptor superfamily and PR is a derivative of estrogen and ER combination. A previous study showed that the tumor-free survival of PR-positive BC patients was significantly longer compared to those of PR-negative BC patients (6). PR may downregulate the expression of breast cancer resistance protein (BCRP) and increase chemosensitivity (7). Our study showed that the expression of PR exhibited statistically significant differences with age and histological grade, which may be related to the presence of independent regulatory pathways affected by PR but not ER. Data also showed that PR expression was decreased in lymph node metastasis. Further analysis demonstrated that the double-positive rate of ER and PR was $39.16 \%$ and it was significantly different in lymph node metastasis and histological grade. Thus, it is essential that ER and PR are assessed as a whole to determine patient prognosis. With the development of the tumor, part of ER-positive and/or PR-positive patients start exhibiting hormone therapy resistance and this 'escape' mechanism of ER and PR requires further investigation $(8,9)$.
HER2, a proto-oncogene, also known as c-erbB-2 or HER2/neu, located on chromosome 17q21, is considered to be closely associated with the occurrence and development of BC (10). Under normal physiological conditions HER2 is inactive; however, once activated, it may enhance tumor invasion and metastasis and increase the degree of malignancy (11). A previous study reported that HER2 overexpression in $\mathrm{BCs}$ indicated poor prognosis (12). Schillaci et al (13) identified NuclErbB-2 positivity as a significant independent predictor of worse overall survival (OS) in patients with MembErbB-2 overexpression. Our results demonstrated that the expressions of ER and PR were significantly correlated with c-erbB-2 status, which was in agreement with findings reported by previous studies $(14,15)$. The presence of HER2 reduced the efficacy of endocrine therapy, therefore, the efficacy of endocrine therapy was increased with targeted inhibition of the expression of HER2 (16). Our study identified an association between HER2 status and the expressions of ER and PR: HER2 overexpression may exert an inhibitory effect on the expressions of ER and/or PR. Our results also demonstrated that the expression of HER2 was enhanced with increasing age and lymph node metastasis; although, these data were not statistically significant. The anti-HER 2 monoclonal antibodies have been used in the clinical treatment of BC patients. However, due to the variations of chromosome 17 and HER2/neu genetic heterogeneity, IHC and FISH assay assessment of HER2 expression is required prior to targeted therapy (17).

Thus far, VEGF is known as the most important angiogenesis-promoting factor, is highly expressed in several malignant tumors and plays an important role in the occurrence, development and metastasis of tumors $(18,19)$. Combining VEGF with $\mathrm{p} 53$ status may result in a better prognostic prediction in BC patients (20). Our results demonstrated that the positive rate of VEGF expression in $\mathrm{BCs}$ was $53.85 \%$ and the positive expression levels were higher in the lymph node metastasis group compared to the non-metastatic group; however, there were no statistically significant differences with age, tumor size, lymph node metastasis and histological grade, a finding consistent with those of Jobim et al (21). Our data also showed that VEGF expression was negatively correlated with ER and 
PR status and positively correlated with HER2 status, which was in agreement with the findings of Linderholm et al (22), who reported that triple-negative BCs (TNBCs) have a higher VEGF level compared to non-TNBC.

EGFR belongs to the tyrosine kinase receptor family and is associated with cell growth, proliferation and differentiation. It was previously demonstrated that $50-70 \%$ of TNBCs express EGFR (23) and EGFR overexpression was associated with TNBCs and unfavorable prognosis (24). TNBCs with a low EGFR expression exhibited a lower incidence of metastasis (25). Our data showed that the positive rate of EGFR expression in BCs was as high as $81.82 \%$ and its expression was significantly correlated with lymph node metastasis and HER2 status $(\mathrm{P}<0.05)$. Its expression in ER- or PR-positive groups was lower compared to that in ER- or PR-negative groups; however, the difference was not statistically significant, which is consistent with the findings of a previous study (26).

The p53 gene is located on human chromosome 17p13.1 and its main function is to induce cell cycle arrest and apoptosis and to promote cell differentiation. The p53 gene may be found as wild-type or mutant and the mutant form prevents the wild-type p53 gene from inhibiting tumor formation, leading to cell transformation and cancerization (27). The five-year survival rate of patients with p53-positive BC was significantly lower compared to that of p53-negative BC patients (28). Our results showed the positive rate of $\mathrm{p} 53$ protein is $46.8 \%$ in $\mathrm{BCs}$, which was statistically correlated with tumor size and histological grade and its expression in the lymph node metastasis group was higher compared to that in the non-metastatic group, although the difference was not statistically significant, which was in agreement with the above viewpoints and the findings of a previous study (29). Futhermore, we observed that the p53 positive expression rates in the ER- or PR-positive groups were lower compared to those in the ER- or PR-negative groups and had a positive correlation with HER2 status, which was in agreement with the findings of previous studies $(29,30)$, indicating that they may exert a synergistic effect on endocrine and targeted therapies.

The TOPO II gene is located on human chromosome 17q21.3 and plays a key role in DNA melting, linking, repair and replication. Our study demonstrated that TOPO II expression in BC tissues was higher in the poor histological grade and lymph node metastasis groups, a finding consistent with those reported by a previous study (31). Therefore, the level of TOPO II expression may reflect the proliferation and metastatic status of BCs, guiding clinical treatment. Our data demonstrated that TOPO II expression exhibited a significant positive correlation with HER2 status, which was in agreement with previous findings (32). We also observed that TOPO II expression was significantly correlated with the status of EGFR, p53 and Ki-67 $(\mathrm{P}<0.05)$, indicating the presence of interactions among these indicators, regulating the progression of tumorigenesis and metastasis of BCs.

$\mathrm{Ki}-67$ is a nuclear antigen related to cell proliferation, only expressed by the proliferating cell nucleus. The expression of Ki-67 is an IHC index detecting cell proliferative activity (33). The levels of $\mathrm{Ki}-67$ expression in BCs were significantly higher compared to those in benign breast lesions and were elevated with increasing cancer cell atypia, which was significant for evaluating the prognosis of BCs $(34,35)$. Our data showed that Ki-67 expression was significantly correlated with poor histological grade and was higher in the lymph node metastasis group compared to the non-metastatic group, indicating that $\mathrm{Ki}-67$ expression is associated with tumor cell differentiation, invasion and metastasis. Ki-67 expression exhibited a significantly positive correlation with HER 2 status, more pronounced in the ER- or PR-negative BCs compared to the ER- or PR-positive BCs, which was in agreement with previous findings (36). Furthermore, our study also demonstrated that the expression of Ki-67 exhibited a significantly positive correlation with cell proliferation-associated nuclear proteins, p53 and TOPO II, suggesting that Ki-67 is closely related to the proliferation of $\mathrm{BC}$ cells.

To divide $\mathrm{BCs}$ into various subtypes is an inevitable trend for the investigation and treatment of BCs. In accordance with the intrinsic genotyping, $\mathrm{BC}$ is divided into four subtypes: Luminal A, Luminal B, HER2/neu and basal-like subtype. Luminal B type was further subdivided into the high Ki-67 expression and HER2-positive subtypes according to Cheang et al (37). However, most experts agree that practically, the results of the detection of ER, PR, HER-2 and $\mathrm{Ki}-67$ indices, equally divide BCs into four types as close substitutes, including Luminal A, Luminal B, HER2/neu and triple-negative subtypes (Table VII). The triple-negative subtype exhibits an almost $80 \%$ overlap with the basal-like subtype. Xue et al (38) collected a total of 5,809 patients with invasive ductal carcinoma and retrospectively analyzed their clinicopathological characteristics and survival rates. Of these patients, $31.1 \%$ were Luminal A, $30.4 \%$ were Luminal B (high Ki-67), 13.1\% were Luminal B (HER2/neu+), 9.0\% were HER2/neu and $16.5 \%$ were triple-negative subtype. The patients with Luminal B subtype were mainly distributed in the lower age group ( $<43$ years old), the HER2/neu subtype was closely associated with tumor size, lymph node-positive status and vascular invasion and the triple-negative BCs were associated with poor histological grade (38). Our study results were mostly consistent with these findings, however, there were also certain differences: for example, the ratio of the patients with the HER2/neu subtype was $26.57 \%$ and it exhibited a significantly negative correlation with age, a finding that was in agreement with those of Munjal et al (39).

In conclusion, the development of malignancy is a process involving multiple factors, genes and steps. Our study demonstrated that ER, PR, HER2, VEGF, EGFR, p53, TOPO II and $\mathrm{Ki}-67$ exhibited high expression levels in invasive $\mathrm{BCs}$ and they also exhibited certain interactions. As regards the associations between these indices and the clinicopathological characteristics of $\mathrm{BCs}$, our results were mostly consistent with those of related previous studies, with certain differences and novel observations. Joint detection of various IHC indices may more accurately determine the biological characteristics and predict the prognosis of $\mathrm{BCs}$, as well as provide a theoretical basis for the diagnosis and treatment of BCs (40). The ongoing scientific investigation may lead to the identification of novel $\mathrm{IHC}$ indices associated with BCs.

\section{Acknowledgements}

This study was supported by the Natural Science Foundation of China (30840093) and the Social Science and Technology Development Projects in Jiangsu (BS2007077). 


\section{References}

1. Liu C, Zhang H, Shuang C, Lu Y, Jin F, Xu H and Lu P: Alterations of ER, PR, HER-2/neu, and P53 protein expression in ductal breast carcinomas and clinical implication. Med Oncol 27: 747-752, 2010

2. Hicks DG and Kulkarni S: HER2+ breast cancer: review of biologic relevance and optimal use of diagnostic tools. Am J Clin Pathol 129: 263-273, 2008.

3. Recăreanu F, Simionescu C, Georgescu CV and Pirici E: Ductal invasive mammary carcinoma - clinicopathological prognostic factors related to immunohistochemical expression of hormonal receptors and Her2/neu oncoprotein. Rom J Morphol Embryol 52: 1059-1064, 2011

4. Woolcott CG, SenGupta SK, Hanna WM and Aronson KJ: Estrogen and progesterone receptor levels in nonneoplastic breast epithelium of breast cancer cases versus benign breast biopsycontrols. BMC Cancer 8: 130, 2008.

5. Walker RA: Immunohistochemical markers as predictive tools for breast cancer. J Clin Pathol 61: 689-696, 2008.

6. Wang ZB, Zhao P, Liu M and Li XH: Expression of ER, PR and Cyclin D1 in breast infiltrating ductal carcinoma and their clinicopathological significance. Zhonghua Yi Xue Za Zhi 85: 514-517, 2005 (In Chinese).

7. Wu X, Zhang X, Zhang H, et al: Progesterone receptor downregulates breast cancer resistance protein expression via binding to the progesterone response element in breast cancer. Cancer Sci 103: 959-967, 2012.

8. Daniel AR, Hagan CR and Lange CA: Progesterone receptor action: defining a role in breast cancer. Expert Rev Endocrinol Metab 6: 359-369, 2011

9. Wargon V, Fernandez SV, Goin M, et al: Hypermethylation of the progesterone receptor $\mathrm{A}$ in constitutive antiprogestin-resistant mouse mammary carcinomas. Breast Cancer Res Treat 126: 319-332, 2011.

10. Gown AM: Current issues in ER and HER-2 testing by IHC in breast cancer. Mod Pathol 21 (Suppl 2): S8-S15, 2008.

11. Guo H and Bai O: Relationship between the expression of ER, PR, Her -2 in breast cancer and its clinical pathological features. Chin J Lab Diagn 12: 1390-1392, 2008.

12. Bagaria SP, Ray PS, Wang J, et al: Prognostic value of basal phenotype in HER2-overexpressing breast cancer. Ann Surg Oncol 19: 935-940, 2012.

13. Schillaci R, Guzmán P, Cayrol F, et al: Clinical relevance of ErbB-2/HER2 nuclear expression in breast cancer. BMC Cancer 12: 74, 2012.

14. Hussein MR, Abd-Elwahed SR and Abdulwahed AR: Alterations of estrogen receptors, progesterone receptors and c-erbB2 oncegene protein expression in ductal carcinomas of the breast. Cell Biol Int 32: 698-707, 2008.

15. Taucher S, Rudas M, Mader RM, et al: Do we need HER-2/neu testing for all patients with primary breast carcinoma? Cancer 98 2547-2553, 2003.

16. Prat A and Baselga J: The role of hormonal therapy in the management of hormonal-receptor-positive breast cancer with co-expression of HER2. Nat Clin Pract Oncol 5: 531-542, 2008.

17. Murthy SS, Sandhya DG, Ahmed F, et al: Assessment of HER2/Neu status by fluorescence in situ hybridization in immunohistochemistry-equivocal cases of invasive ductal carcinoma and aberrant signal patterns: a study at a tertiary cancer center. Indian J Pathol Microbiol 54: 532-538, 2011.

18. Kowanetz $M$ and Ferrara N: Vascular endothelial growth factor signaling pathways: therapeutic perspective. Clin Cancer Res 12: 5018-5022, 2006

19. Zhao YC, Ni XJ, Wang MH, Zha XM, Zhao Y and Wang S: Tumor-derived VEGF-C, but not VEGF-D, promotes sentinel lymph node lymphangiogenesis prior to metastasis in breast cancer patients. Med Oncol 29: 2594-2600, 2012.

20. Linderholm BK, Lindahl T, Holmberg L, Klaar S, Lennerstrand J, Henriksson R and Bergh J: The expression of vascular endothelial growth factor correlates with mutant p53 and poor prognosis in human breast cancer. Cancer Res 61: 2256-2260, 2001.

21. Jobim FC, Schwartsmann G, Xavier NL, et al: Expression of MMP-9 and VEGF in breast cancer: correlation with other prognostic indicators. Rev Bras Ginecol Obstet 30: 287-293, 2008 (In Portuguese).
22. Linderholm BK, Hellborg H, Johansson U, et al: Significantly higher levels of vascular endothelial growth factor (VEGF) and shorter survival times for patients with primary operable triple-negative breast cancer. Ann Oncol 20: 1639-1646, 2009.

23. Burness ML, Grushko TA and Olopade Ol: Epidermal growth factor receptor in triple-negative and basal-like breast cancer: promising clinical target or only a marker? Cancer J 16: 23-32, 2010.

24. Kallel I, Khabir A, Boujelbene N, et al: EGFR overexpression relates to triple negative profile and poor prognosis in breast cancer patients in Tunisia. J Recept Signal Transduct Res 32: 142-149, 2012.

25. Viale G, Rotmensz N, Maisonneuve P, et al: Invasive ductal carcinoma of the breast with the 'triple-negative' phenotype: prognostic implications of EGFR immunoreactivity. Breast Cancer Res Treat 116: 317-328, 2009

26. Skobe M, Hawighorst T, Jackson DG, et al: Induction of tumor lymphangiogenesis by VEGF-C promotes breast cancer metastasis. Nat Med 7: 192-198, 2001.

27. Kazemi M, Salehi Z and Chakosari RJ: TP53 codon 72 polymorphism and breast cancer in northern Iran. Oncol Res 18: 25-30, 2009.

28. Dookeran KA, Dignam JJ, Ferrer K, et al: p53 as a marker of prognosis in African-American women with breast cancer. Ann Surg Oncol 17: 1398-1405, 2010.

29. González-Rodilla I, Verna V, Muñoz AB, Estévez J, Boix M and Schneider J: Expression of the apoptosis-related genes Bcl-2 and p53 in clinical samples from endometrial carcinoma patients. Anticancer Res 31: 4191-4193, 2011.

30. Mao XY, Fan CF, Zheng HC, Wei J, Yao F and Jin F: p53 nuclear accumulation and ERalpha expression in ductal hyperplasia of breast in a cohort of 215 Chinese women. J Exp Clin Cancer Res 29: 112, 2010.

31. Tokiniwa H, Horiguchi J, Takata D, et al: Topoisomerase II alpha expression and the Ki-67 labeling index correlate with prognostic factors in estrogen receptor-positive and human epidermal growth factor type-2-negative breast cancer. Breast Cancer 19: 309-314, 2012.

32. Tanner B, Pilch H, Schäffer U, et al: Expression of c-erbB-2 and topoisomerase II alpha in relation to chemoresistance in ovarian cancer. Zentralbl Gynakol 124: 176-183, 2002 (In German).

33. Urruticoechea A, Smith IE and Dowsett M: Proliferation marker Ki-67 in early breast cancer. J Clin Oncol 23: 7212-7220, 2005.

34. de Azambuja E, Cardoso F, de Castro G Jr, et al: Ki-67 as prognostic marker in early breast cancer: a meta-analysis of published studies involving 12,155 patients. Br J Cancer 96: 1504-1513, 2007.

35. Dowsett M, Nielsen TO, A'hern R, et al: Assessment of Ki67 in breast cancer: recommendations from the International Ki67 in Breast Cancer Working Group. J Natl Cancer Inst 103: 1656-1664, 2011.

36. Endo Y, Toyama T, Takahashi S, et al: High estrogen receptor expression and low Ki67 expression are associated with improved time to progression during first-line endocrine therapy with aromatase inhibitors in breast cancer. Int J Clin Oncol 16: 512-518, 2011.

37. Cheang MC, Chia SK, Voduc D, et al: Ki67 index, HER2 status, and prognosis of patients with Luminal B breast cancer. J Natl Cancer Inst 101: 736-750, 2009.

38. Xue C, Wang X, Peng R, et al: Distribution, clinicopathologic features and survival of breast cancer subtypes in Southern China. Cancer Sci 103: 1679-1687, 2012

39. Munjal K, Ambaye A, Evans MF, Mitchell J, Nandedkar S and Cooper K: Immunohistochemical analysis of ER, PR, Her2 and CK5/6 in infiltrative breast carcinomas in Indian patients. Asian Pac J Cancer Prev 10: 773-778, 2009.

40. Moriya T, Kanomata N, Kozuka Y, et al: Molecular morphological approach to the pathological study of development and advancement of human breast cancer. Med Mol Morphol 43: 67-73, 2010. 